\title{
Information Code-Switching: A Study of Language Preferences in Academic Libraries
}

\author{
Frans Albarillo
}

Initially coined by sociolinguists, the term code-switching refers to the alternation of languages by multilinguals. Code-switching is an active research area that has significant implications for academic libraries. Using data from focus groups and a survey tool, this paper examines language preferences of foreign-born students for particular information tasks. The main finding is that students' culture and language represent an active influence on and important part of their identity, information consumption, and academic socialization. The author discusses the practical implications of these findings on academic library services in relation to ACRL's 2012 Diversity Standards Cultural Competency with an emphasis on standard 6, linguistic diversity.

\section{Introduction}

This paper is about foreign-born students' language preferences and information use in academic libraries. Based on a quantitative and qualitative data set collected by the author, this study examines a concept called code-switching, a linguistic phenomenon where speakers change between two or more languages or between varieties of a language within a speech act or discourse. ${ }^{1}$ The author was concerned with how individuals switch languages for different information tasks. Since information is coded in language, the author will refer to the phenomenon as simply information code-switching, referring to switching languages for a particular information task. The author coined the term "information code-switching" to distinguish it as a kind of code-switching that refers specifically to the preferences of a person when it comes to choosing a language or dialect for a particular kind of information behavior.

The basic research question the author investigates is whether there are types of information activities and places where multilingual students code-switch. The answer is yes. The data analyzed here, from focus groups and a survey, show how code-switching works in relation to topics of concern to academic libraries. Librarians are interested in providing access to resources, creating a friendly and welcoming environment, and accommodating the behaviors and preferences of the library's users. This paper provides qualitative and quantitative evidence that foreign-born students who use academic

*Frans Albarillo is Assistant Professor/Reference \& Instruction at Brooklyn College, City University of New York; e-mail: falbarillo@brooklyn.cuny.edu. (C2018 Frans Albarillo, Attribution-NonCommercial (http://creativecommons.org/licenses/by-nc/4.0/) CC BY-NC. 
libraries do switch languages when communicating and use different languages for different kinds of information tasks.

This triangulated approach shows a nuanced picture of the language preferences and information use of foreign-born students as a student population. For students with another language besides English, these data show that language and information use and seeking are intertwined. Even though English is widely considered to be the language of the academy, non-English languages are spoken in academic libraries all the time and used for a variety of information seeking and media consumption. Code-switching has many implications for library service, especially relating to professional standard 6, Linguistic Diversity, of ACRL's 2012 Diversity Standards Cultural Competency for Academic Libraries, as will be examined in the discussion section.

\section{Literature Review}

This literature review is a selective review of the vast literature on code-switching (CS), covering some key studies and works in CS. In the literature, code-switching can also be referred to as "codeswitching" or "code switching." This author chooses to use the hyphenated version, as it appears in a seminal article by Jan-Peter Blom and John Gumperz describing code-switching in Norway between two language varieties, Ranamål and Bokmål. In their study, Blom and Gumperz look for "social meaning" in how people use their "linguistic repertoire." ${ }^{2}$ Ranamål is a "prestige" dialect and Bokmål is a standard language taught in schools in northern Norway. ${ }^{3}$ Blom and Gumperz describe CS: "In their everyday interactions, they [people in the village of Hemnesberget] select among the two as the situation demands. Members view this alternation as a shift between two distinct entities, which are never mixed. A person speaks one or the other." ${ }^{4}$ Carol Myers-Scotton, a linguist writing in the 1990s about research in code-switching, summarizes Gumperz's characterization of CS as the use of language codes as a type of "social strategy" and extends it to include not only changing languages for content, but speakers using it to frame discourse to show social meanings like solidarity or power relations. ${ }^{5}$ Similarly, in the data for this paper, the author will discuss how languages are used strategically for different kinds of information including normal situational and demographic contexts like language choice at home as an expression of cultural identity.

Another concept that is important to this discussion is the notion of a language domain, or the context in which a certain language is chosen. Joshua Fishman traces the history of this concept in his article on the topic, and defines domains as created by "institutional contexts" and their "congruent behavioral co-occurrences." ${ }^{6}$ Fishman further elaborates that domains can have different settings, have a "sociopsychological" component, and, most important, the "domain is a sociocultural construct abstracted from topics of communications, relationships between communicators, and locales of communication, in accord with institutions of a society and the spheres of activity of a speech community, in such a way that individual behavior and social patterns can be distinguished from each other and yet be related to each other." ${ }^{17}$ Fishman's domain model of language use is the construct used in this study. While Fishman did not initially consider libraries as a separate domain from school, in this study the author looks at information code-switching as an extension of the domain model to language use in libraries. An extended analysis of Fishman's concept of linguistic domain is given by L.B. Breitborde: "A domain is not the actual interaction (the setting), but an abstract set of relationships between status, topic, and locale which gives meaning to the events that actually comprise social interaction." ${ }^{\prime \prime}$ In the case of academic libraries in the United States, the status of non-English languages and their presence in library collections, signage, and user experiences are rarely discussed, and, in most cases, languages other than English are invisible. 
Fishman includes several domains in his language census of 431 individuals in a Puerto Rican neighborhood in Jersey City, such as "home, church, school, work place, and beach." ${ }^{9}$ In his language census, Fishman asks his respondents about their language abilities in English and Spanish, including "reading, writing, understanding, and speaking, writing letters, language of instruction, conversational languages, etc." ${ }^{10}$ In this paper, the language questions were designed in a similar manner using Fishman's work and the language questions in the Children of Immigrants Longitudinal Study (CILS). ${ }^{11}$ Language domains allow bilinguals to use their linguistic repertoires for a variety of social functions, according to Breitborde: "The use of their linguistic repertoire by bilingual speakers has been linked to situation, setting, social relationships, identity, and topic."12 The relationships, identity, and topics in this paper involve the academic library and the relationships foreign-born students have to information topics, tasks, and people as mediated through language.

Another oft-cited code-switching study is by Shana Poplack, who examines Puerto Rican Spanish and English in New York City. ${ }^{13}$ Poplack provides examples of "intrasentential" CS, where English and Spanish are mixed in the same sentence. For example, "Me iban a layoff" is translated as "They were going to lay me off"14 and includes both English and Spanish in the same sentence. Poplack also notes the influence of Spanish phonology on the perfectly formed grammatical English when "That's what he said" is pronounced "[da "wari se]." ${ }^{15}$ And Poplack reports that most of the CS discourses were grammatical: "Perhaps the most striking result of this study is that there were virtually no instances of ungrammatical combinations of L1 and L2 [first language and second language] in the 1,835 switches studied, regardless of the bilingual ability of the speaker." ${ }^{16}$ Another important finding by Poplack is the positive attitude of the speakers who code-switched more toward their language. ${ }^{17}$ This landmark research underscores how important CS is for multilingual individuals in defining social relations when speakers have access to more than one language. CS has a situational context, in terms of location, prestige, and institutional support. CS is fluid and natural and is not something that is planned ahead of time. Furthermore, switches have grammatical patterns and should not be seen as "broken" utterances. A significant theme in CS research aims at dispelling these myths about ill-formed languages and dialects. The languages in an individual's linguistic repertoire will be important to the individual's or community's identity, and it is important to think about how libraries recognize or do not recognize languages through their signage, public services, collection development, and implementation of technology.

CS as a research topic today has crossed from linguistics into fields including education, English composition studies, and cultural studies. A search using "codeswitching OR code switching OR code-switching" in the Scopus Social Science and Humanities Index (limiting the search to articles) shows that there were 67 articles published about code-switching in 2016. For a fascinating look at CS in hip-hop the author recommends the book Global Linguistic Flows: Hip Hop Cultures, Youth Identities, and the Politics of Language by Samy Alim, Awad Ibrahim, and Alastair Pennycook. Sociolinguist Jannis Androutsopoulos's chapter "Language and the Three Spheres of Hip-Hop" has a fascinating discussion on how English is used in code-switching and code-mixing to exemplify style, social identity, and glocality [global and local practices] when English is code-switched or code-mixed with a non-English language. ${ }^{18}$ While hip hop is one artistic genre where language and code-switching play a major role in global media communities, the localization of English into specific local varieties is a rich and thriving academic field of study called World Englishes. This field of study recognizes that "The unprecedented spread of English has not [led] to a uniform global language; English is indigenizing into new vernaculars and specializing into national and international 
varieties of the lingua franca. As Mufwene puts it, 'rather than driving the world towards monolingualism, differential evolution of English appears to be substituting a new form [of] diversity for an older one' (2013:50).'"19 Although this paper does not focus on World Englishes or code-switching between varieties of a single language, an instance of this can be seen in the qualitative data when students dialect-shift to British Standard English - their preferred variety of English when looking for news media.

Language teaching is another field that actively researches code-switching. A recent example is the work of Marta Fairclough and Flavia Belpoliti, who examine codeswitches in the writing of English/Spanish heritage language learners to look at the transfer of vocabulary from English to Spanish. ${ }^{20}$ A heritage language learner (HLL) is "an individual who is raised in a home where a non-English language is spoken." ${ }^{21}$ Fairclough and Belpoliti investigate how code-switching between English and Spanish improves HLLs' Spanish literacy by analyzing essays written in response to a prompt measuring a learner's vocabulary in the language they are trying to learn. ${ }^{22}$ As an occurrence closely associated with globalization and transnationalism, CS is a popular phenomenon to study as a topic that involves multilingualism, language instruction, and education. The topic of CS is very relevant today, as other disciplines incorporate this behavior into their research areas. The current study is not a linguistic study or education study; rather, it looks at how an understanding of CS can be applied to academic libraries as an important site to study the intersections of culture, language, information, and immigration.

The same search described above for "codeswitching OR code switching OR codeswitching," when done in Library, Information Science \& Technology Abstracts and Library \& Information Science Source, returned only two results. The first article, by Magdalena Malechová, discusses code-switching as an intercultural communication trend and a contact linguistic phenomenon. ${ }^{23}$ Contact linguistics is a subdiscipline of linguistics that has an active history of research in CS. For data, Malechová's article counts occurrences of "grammatical code-switching" between English and German in two online German newspapers, concluding that CS is a "strong communication trend." ${ }^{24}$ The second result is an article by Bettina Kümmerling-Meibauer, who analyzes the "visual codes" 25 in Korean and Iranian bilingual picture books for children. She concludes that, in addition to having two separate languages, multilingual picture books have "an elaborate visual code, that are both universal and cultural," which needs to be accounted for in how children are taught to read. ${ }^{26}$ Malechová's work and Kümmerling-Meibauer's study show how CS is being extended to analyze media and visual codes, respectively. At the time of writing, the author could not find articles in any library and information science journals on code-switching. This study aims to fill that gap by providing examples of CS by foreign-born students in an academic library context. This study also aims to persuade librarians that information code-switching, or the use of different languages for different information tasks, is a research area that librarians can pursue to understand the role that language plays in the information behavior of multilingual individuals. For librarians working with multilingual populations, it is important to be aware of CS and how populations use their languages to consume information and media in academic libraries. While there are no articles specifically on code-switching in library and information science journals, there are a range of works that look at language issues in libraries.

\section{Language in Libraries}

Research about language in libraries exists in the literature and can be found as a topic associated with populations like international students ${ }^{27}$ and immigrants. ${ }^{28}$ Considering the complexity of the relationship between language and information, very few studies 
exist that look directly at language preferences, language attitudes, bilingual outreach, and linguistic diversity. At the time of writing, a study by Ignacio Ferrer-Vinent on language preferences at the reference desk ${ }^{29}$ is the only study that directly investigates language preferences in academic libraries with reference interactions. This is a rich area that needs further exploring. In relation to library instruction, work by scholars like Karen Bordonaro ${ }^{30}$ on students of English as a second language is an important example of how language learning happens in the academic information-seeking context. Sara Luly and Holger Lenz apply the model for Language Oriented Library Instruction $(\mathrm{LOLI})^{31}$ to learners of German as a foreign language, who have varying pedagogical needs compared to international students and immigrant students. A critical gap that no one has looked at is how librarians need to vary their instruction according to the different library populations: international students, immigrant students, generation 1.5 students, and foreign language learners. The author has written a literature review about these various different kinds of English language learners ${ }^{32}$ and how important it is to distinguish between these populations. In addition to this variation across the kinds of English language learners, it is also important that librarians learn about the varieties of Englishes that students can speak, with attention to World Englishes, as there may be more than one kind of English used in the classroom and the library. Sonia Smith's article "Library Instruction for Romanized Hebrew" discusses her experiences at McGill University in Canada creating a library instruction session to help students in an advanced Hebrew class navigate the romanized Hebrew catalog records. ${ }^{33}$ Smith emphasizes how important the role of library instruction ${ }^{34}$ is to scholars who wish to access scholarly materials that are romanized in the library catalog. There is a lively discussion on romanization, language, and access of titles in non-Latin scripts in the journal Cataloging $\mathcal{E}$ Classification Quarterly; these languages include Persian, ${ }^{35}$ Korean, ${ }^{36}$ and Japanese..$^{37}$ The author has also discussed issues of romanization and transliteration as barriers to accessing content in library databases in his article "Evaluating Language Functionality in Library Databases." ${ }^{\prime 38}$ For outreach to international students, academic librarians Xiang Li, Kevin McDowell, and Xiaotong Wang write about their experiences creating videos about the library in Arabic, Chinese, English, Japanese, and Korean to help international students "navigate new systems and to bridge the gap between past library experiences and US academic library settings." ${ }^{39}$

Language is an important aspect of cultural competency. In a survey by Misa Mi and Yingting Zhang, two health sciences librarians exploring their perceptions of culturally competent library services, they found that "...those who spoke another language in addition to English rated their own levels of cultural competency higher than those who only spoke English. Those with the ability to speak another language might have an advantage of better understanding a given culture, which could lead to higher levels of cultural awareness and sensitivity." ${ }^{40} \mathrm{Mi}$ and Zhang go on to argue that "Culturally competent librarians should regard the ability to speak a second language as an asset that demonstrates greater cognitive ability [33], rather than a deficiency [5]. It would be worthwhile for librarians to develop awareness and knowledge of language differences (which does not require an ability to speak that language) that are reflected in verbal and nonverbal communication processes and norms for effective cross-cultural interactions with and service provision for users from different backgrounds." ${ }^{41}$ The author agrees with $\mathrm{Mi}$ and Zhang that, in general, second languages should be viewed as a form of cultural capital, and a cognitive advantage, and that multilingual individuals are more sensitive to cultural differences that they negotiate daily in their lives as speakers of minority languages. It is important to be conscious of essentializing culture into language. While language is an important facet of culture, there are other dimensions of culture like race, ethnicity, and religion that are also meaningful 
cultural factors. However, the focus of this article is language, and because language is a part of cultural competency, the author recommends that managers should hire multilingual individuals, or at least include multilingualism as a preferred qualification in job advertisements. Managers should also provide training for monolingual staff who work with multilingual populations.

Linguistic diversity training is often ignored in organizational contexts. By linguistic diversity training, the author means education on accents, creoles, code-switching, identifying relevant varieties of English (World Englishes) and other linguistic facets that characterize the patron population. Additionally, it's important for librarians to understand that language groups like Russian, French, Spanish, or Mandarin are often lingua francas for other linguistic minorities. Ideally, multilingual colleagues could talk about their language use with their monolingual colleagues to increase their awareness of linguistic diversity. For example, the Spanish language is incredibly diverse; and, in areas where it is spoken, cross-cultural trainings could be led by the individuals in the library who speak it so that people who are not aware of these differences can be mindful and at the very least know that differences exist in spoken Spanish that could indicate race, ethnicity, identity, religion, and other potential categories that a speaker may self-identify with. Knowing about linguistic diversity and linguistic behaviors like code-switching is important in the goal of becoming a culturally competent organization. Medical librarians have created a roadmap for hospitals ${ }^{42}$ to move their organizations closer, and the author believes that it is important for academic libraries to do the same by studying the demographic effects of factors like language, race, ethnicity, income, age, gender, and able-bodiedness, and how these factors affect or influence library use.

\section{Methodology}

With approval from the City University of New York Institutional Review Board and using a small grant awarded by the PSC-CUNY Research Award Program, the author conducted focus group interviews in the spring of 2014 and a survey in the fall of 2014.

\section{Population and Data Collection Procedures}

The author used SurveyMonkey, an online survey tool, to create a survey to screen candidates for focus groups. A link to the screening survey was posted on flyers around campus to recruit foreign-born students. The total number of responses for the screening survey was 66, with 33 complete replies and 4 respondents who did not meet the main selection criteria (at least 1 year of high school in their home country and a current student at Brooklyn College at the graduate or undergraduate level). There were a total of 29 qualified respondents and a 45 percent response rate (\# interviewed / \# eligible to participate). Thirteen students participated in the focus groups. Recruiting for the focus groups was difficult, and the focus groups were very small, ranging from 2 to 4 individuals per group. Participants received \$20 each to take part in the focus group. The interviews were semistructured, took 45 minutes to 1 hour to complete, and were based on the following prompts: What languages do you use in your daily life? What does research mean to you? How do you do research? The author recorded the data using a Zoom $\mathrm{H} 2$ audio recorder and transcribed the recordings in NVivo.

The main survey was designed during and after the 2014 summer Institute of Research Design in Librarianship. Before launching the survey, the author did a pilot test of the survey with students who participated in the focus groups. The author hired a research assistant for the survey portion of the study, and together the researchers piloted the survey, used a screening survey to recruit survey participants, and collected data during the fall 2014 semester. Flyers were distributed on campus advertising the study with a link to the screening survey. The researchers also staffed an informational table about 
the survey in various spaces around the campus, including the library. Several offices agreed to promote the screening survey on their Facebook pages and their mailing lists (Women's Center, the Office of Graduate Admissions, and the office of student activities). The screening survey collected demographic and educational background information, which allowed researchers to include participants based on the following criteria:

- Participants are foreign-born

- Participants are undergraduate and graduate students

Qualifying participants received an e-mail with a link to the full survey within two days of completing the screening survey. The full survey took 30 to 40 minutes to complete and was divided into the following parts: demographics, educational background, language use, library use, and cultural questions (including views on American-style research). For this paper the author examines the data from the language use and demographics sections.

Because the survey was linked to their e-mail, respondents could finish one part of the survey and return to the survey at another time to complete the other parts. The researchers sent out e-mails to remind participants that they needed to complete the full survey. Once SurveyMonkey indicated that a survey was complete, the researchers made an appointment with the student via e-mail to distribute the $\$ 10$ incentive.

Participants also had the option of doing an in-person survey, where the researcher would help the participant complete the survey in a classroom setting, after which they would immediately receive their incentive, though none of the eligible participants chose this option.

There were 3,004 foreign-born students at Brooklyn College in the fall 2014 semester. ${ }^{43}$ A total of 274 students were screened, and 123 eligible students were invited to participate in the full survey. Of these, 103 responded and participated. Ten surveys contained partial responses and were discarded, and one survey was discarded because the person self-reported low English reading and writing ability. For this paper, 92 complete surveys were analyzed. The survey response rate was 74 percent (\# complete surveys / \# eligible to participate).

\section{Survey Data and Analysis}

The author downloaded the survey data from SurveyMonkey and analyzed CS and language use data in Excel, and then in SPSS 21 using independent samples t-tests to look for associations between mean scores in language use variables (CS, language domains, information tasks, and language ability) and demographic grouping variables, which include student status (undergraduate or graduate), immigration status (permanent or temporary status), first-generation student status, gender, and race/ethnicity. T-tests were not conducted for grouping variables that had fewer than 10 respondents (for example, there were only 5 respondents who identified as Hispanic and 2 respondents who identified as Middle Eastern). The author used Somers' $\mathrm{d}$ test to look for associations between language use variables and the following dependent variables: age, age arrived in the United States, years lived in the United States, and median income (estimated from the 2014 American Community Survey ${ }^{44}$ using respondent zip codes).

The author has chosen to treat the Likert-type variables as continuous rather than ordinal. The survey data meet all the assumptions for an independent samples t-test ${ }^{45}$ and the Somers' $\mathrm{d}$ test for associations. ${ }^{46}$ The author has carefully followed Arlene Fink's survey methods book ${ }^{47}$ in this analysis.

The author created a variable called code-switching based on the following survey question:

I switch between English and my non-English language(s)

a. Always

b. Very frequently 

c. Occasionally
d. Rarely
e. Very rarely
f. Never

The author coded this variable in SPSS 21 ( 1 = Never, $6=$ Always).

The grouping variables for language domains and information tasks were created from a matrix as shown in figures 1 and 2, with Language 2 (L2) referring to the main language the student spoke in addition to English.

\begin{tabular}{|l|l|c|c|c|c|c|}
\hline \multicolumn{7}{|c|}{ MIGURE 1 } \\
& $\begin{array}{c}\text { Mome } \\
\text { use (at } \\
\text { home) }\end{array}$ & $\begin{array}{c}\text { Educational } \\
\text { use (at } \\
\text { school or } \\
\text { college) }\end{array}$ & $\begin{array}{c}\text { Professional } \\
\text { or work use } \\
\text { (at work) }\end{array}$ & $\begin{array}{c}\text { Friends } \\
\text { (with } \\
\text { friends) }\end{array}$ & $\begin{array}{c}\text { Family } \\
\text { (with } \\
\text { family) }\end{array}$ & $\begin{array}{c}\text { I am very } \\
\text { comfortable } \\
\text { using this } \\
\text { language }\end{array}$ \\
\hline English & & & & & & \\
\hline Language 2 & & & & & & \\
\hline
\end{tabular}

\begin{tabular}{|l|l|l|l|l|l|l|l|l|}
\hline \multicolumn{7}{|c|}{ MIGURE 2 } \\
\hline & $\begin{array}{l}\text { Watching } \\
\text { movies }\end{array}$ & $\begin{array}{l}\text { Listening } \\
\text { to music }\end{array}$ & $\begin{array}{l}\text { Social } \\
\text { media } \\
\text { (Facebook, } \\
\text { Twitter, } \\
\text { Weibo) }\end{array}$ & $\begin{array}{l}\text { Instant } \\
\text { messaging } \\
\text { (IM) }\end{array}$ & $\begin{array}{l}\text { Reading } \\
\text { news } \\
\text { and } \\
\text { current } \\
\text { events }\end{array}$ & $\begin{array}{l}\text { Texting/ } \\
\text { SMS }\end{array}$ & $\begin{array}{l}\text { Communicating } \\
\text { on emails }\end{array}$ & $\begin{array}{l}\text { Phone } \\
\text { and } \\
\text { voice } \\
\text { calls }\end{array}$ \\
\hline $\begin{array}{l}\text { I prefer } \\
\text { English }\end{array}$ & & & & & & & & \\
\hline $\begin{array}{l}\text { I prefer } \\
\text { L2 }\end{array}$ & & & & & & & & \\
\hline
\end{tabular}

The responses were dummy-coded $(0=$ no attribute, $1=$ presence of the attribute).

The variable for language ability was created from the questions below with responses coded in a five-point Likert-type scale $(1=$ not at all, $5=$ very well $)$.

How well do you speak English?

How well do you understand English?

How well do you read English?

How well do you write English?

How well do you speak $L 2$ ?

How well do you understand L2?

How well do you read L2?

How well do you write L2?

The first of the demographic variables, student status, was determined by the following question:

Are you a high school, undergraduate, or graduate student?

a. I am not a student [disqualify]

b. I am a high school student [disqualify]

c. I am an undergraduate student

d. I am a graduate student 
The author used two questions in the survey that asked about immigration status to construct two variables: permanent immigration status and temporary immigration status. The first question was asked in the screening survey: Are you an international student with one of the following visas: $F, J, M, A, H 1 B$, or $K$ ? ( $a$. Yes $b$. No) The second question was asked in the main survey:

What is your immigration status?

a. U.S. citizen

b. U.S. citizen by naturalization

c. Permanent resident

d. Not a U.S. citizen

e. Dual citizenship or nationality

f. Deferred Action for Childhood Arrivals ("DACA")

g. I do not wish to answer this question

h. I don't know

Respondents who chose $a, b, c$, or e in the main survey were grouped as permanent, and dummy-coded in SPSS $(0=$ not permanent, $1=$ permanent $)$. Respondents who chose $\mathrm{a}$ in the screening survey question and $\mathrm{d}$ or $\mathrm{f}$ in the main survey question were grouped as temporary status.

Gender, age, age arrived in the United States, years in the United States, and zip code were constructed from the survey questions below.

What is your gender? a. Male b. Female

What year were you born? [numerical text field]

What year did you move to the United States? [numerical text field]

What is your current zip code? [numerical text field]

First-generation college students were identified using the following question: Ideally, what's your intention for completing a degree? Check all that apply. Nineteen answers were available, and respondents could choose as many as applied; answer L, "I am the first in my family to get a college degree," was used to identify first-generation college students. The author dummy-coded the variable $(0=$ not a first-generation college student, 1 = first-generation college student).

Race and ethnicity categories were taken from adapted from a White House document on reporting race..$^{48}$ The question appeared as follows in the survey:

TABLE 1 Focus Group Demographics

\begin{tabular}{|l|c|c|}
\hline \multirow{2}{*}{ Gender } & Men & 3 \\
\cline { 2 - 3 } & Women & 10 \\
\hline \multirow{3}{*}{ Age } & 25 to 34 & 4 \\
\cline { 2 - 3 } & 18 to 24 & 7 \\
\cline { 2 - 3 } & 35 to 44 & 2 \\
\hline \multirow{2}{*}{$\begin{array}{l}\text { Length of } \\
\text { time in the }\end{array}$} & Median & 3 years \\
\cline { 2 - 3 } US & Mean & 5.2 years \\
\cline { 2 - 3 } & Mode & 1 year \\
\hline
\end{tabular}

Please indicate your race:

a. Hispanic or Latino (a person of Cuban, Mexican, Puerto Rican, South or Central American, or other Spanish culture or origin, regardless of race)

b. American Indian or Alaska Native (a person having origins in any of the original peoples of North and South America, including Central America, who maintains cultural identification through tribal affiliation or community attachment)

c. Asian (a person having origins in any of the original peoples of the Far East, Southeast Asia, or the Indian Subcontinent, including, for example, Cambodia, China, India, Japan, Korea, Malaysia, Pakistan, the Philippine Islands, Thailand, and Vietnam)

d. Black or African American (a person having origins in any of the black racial groups of Africa) 
e. Native Hawaiian or Other Pacific Islander (a person having origins in any of the original peoples of Hawaii, Guam, Samoa, or other Pacific Islands)

f. White (a person having origins in any of the original peoples of Europe)

g. Middle Easterner (a person having origins from the Middle Eastern countries)

$h$. North African (a person having origins from the North African countries)

i. From multiple races

j. Other (please specify)

The author dummy-coded all the race and ethnicity variables.

Figure 3 shows the binary grouping variables.

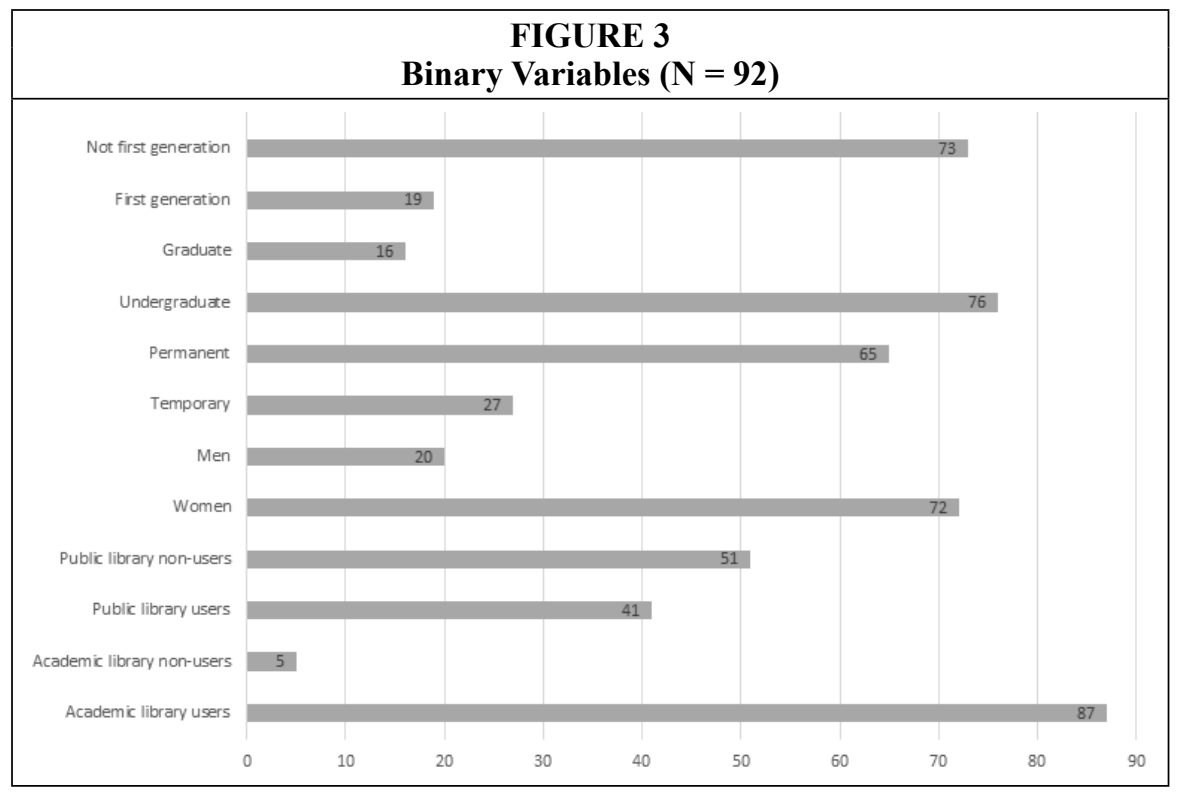

Finally, reading preferences were created from the matrix in figure 4 . The author created variables for language preference for academic and nonacademic reading to determine whether students who are more likely to code-switch prefer a particular language for academic and leisure reading.

\begin{tabular}{|l|l|l|l|l|}
\hline \multicolumn{5}{|c|}{ FIGURE 4 } \\
\hline & $\begin{array}{l}\text { Academic } \\
\text { reading (books, } \\
\text { e-books, } \\
\text { articles, etc.) }\end{array}$ & $\begin{array}{l}\text { Nonacademic } \\
\text { reading (books, } \\
\text { e-books, } \\
\text { articles, etc.) }\end{array}$ & $\begin{array}{l}\text { Internet } \\
\text { searching } \\
\text { for academic } \\
\text { purposes }\end{array}$ & $\begin{array}{l}\text { Internet } \\
\text { searching NOT } \\
\text { for academic } \\
\text { purposes }\end{array}$ \\
\hline I prefer English & & & & \\
\hline I prefer L2 & & & & \\
\hline
\end{tabular}

\section{Results}

The data illustrate that students who speak a language besides English are more likely to do so in certain language domains such as home, school, or with friends. The ability of students to speak in English and their second language is also associated with how likely these students are to switch between languages. 
Independent samples t-tests (hereafter t-tests) were not conducted for race and ethnicity categories with fewer than 10 respondents, which included Hispanic, American Indian, Native Hawaiian, Middle Easterner, North African, and multiple races. The t-tests showed that the following variables did not have a statistical difference in the mean reported CS score for the multilingual respondents:

- Gender

- Immigration status

- Student status

- First-generation status

- White or nonwhite (race and ethnicity variable)

- Other (race and ethnicity variable)

The author found no associations using Somers' d test between reported CS and the following variables:

- Age

- Years in the United States

- Median income based on zip code

- Ability to speak English

- Ability to understand L2 [language spoken other than English]

- $\quad$ Ability to write L2

Table 2 shows the variables where the author found that foreign-born students are very likely to switch to L2 (the non-English language) for information tasks and in linguistic domains such as home, school, and with friends.

\begin{tabular}{|c|c|c|c|c|c|c|}
\hline \multicolumn{7}{|c|}{$\begin{array}{c}\text { TABLE } 2 \\
\text { Independent Samples T-Tests }\end{array}$} \\
\hline DV & $\begin{array}{l}\text { Variable } \\
\text { Name }\end{array}$ & IV & $\mathbf{N}$ & Mean & Sig & $\begin{array}{c}\text { Mean } \\
\text { Difference }\end{array}$ \\
\hline \multirow[t]{2}{*}{$\begin{array}{l}\text { Code- } \\
\text { switch }\end{array}$} & \multirow[t]{2}{*}{ Music } & $\begin{array}{l}\text { I do not prefer L2 for listening } \\
\text { to music }\end{array}$ & 60 & 3.33 & \multirow[t]{2}{*}{0.001} & \multirow[t]{2}{*}{1.417} \\
\hline & & I prefer L2 for listening to music & 32 & 4.75 & & \\
\hline \multirow[t]{2}{*}{$\begin{array}{l}\text { Code- } \\
\text { switch }\end{array}$} & \multirow[t]{2}{*}{$\begin{array}{l}\text { Academic } \\
\text { Reading }\end{array}$} & $\begin{array}{l}\text { I do not prefer } \mathrm{L} 2 \text { for academic } \\
\text { reading }\end{array}$ & 82 & 3.76 & \multirow[t]{2}{*}{0.04} & \multirow[t]{2}{*}{0.644} \\
\hline & & I prefer L2 for academic reading & 10 & 4.4 & & \\
\hline \multirow[t]{2}{*}{$\begin{array}{l}\text { Code- } \\
\text { switch }\end{array}$} & \multirow[t]{2}{*}{$\begin{array}{l}\text { Social } \\
\text { Media }\end{array}$} & $\begin{array}{l}\text { I do not prefer to use L2 for } \\
\text { social media }\end{array}$ & 70 & 3.57 & \multirow[t]{2}{*}{0.004} & \multirow[t]{2}{*}{1.065} \\
\hline & & $\begin{array}{l}\text { I prefer to use L2 for social } \\
\text { media }\end{array}$ & 22 & 4.64 & & \\
\hline \multirow[t]{2}{*}{$\begin{array}{l}\text { Code- } \\
\text { switch }\end{array}$} & \multirow[t]{2}{*}{$\begin{array}{l}\text { Academic } \\
\text { Internet } \\
\text { Searching }\end{array}$} & $\begin{array}{l}\text { I do not prefer to use L2 to } \\
\text { search the Internet for academic } \\
\text { purposes }\end{array}$ & 80 & 3.71 & \multirow[t]{2}{*}{0.013} & \multirow[t]{2}{*}{0.871} \\
\hline & & $\begin{array}{l}\text { I prefer to use } \mathrm{L} 2 \text { to search the } \\
\text { Internet for academic purposes }\end{array}$ & 12 & 4.58 & & \\
\hline \multirow[t]{2}{*}{$\begin{array}{l}\text { Code- } \\
\text { switch }\end{array}$} & \multirow[t]{2}{*}{$\begin{array}{l}\text { Leisurely } \\
\text { Internet } \\
\text { Searching }\end{array}$} & $\begin{array}{l}\text { I do not prefer to use L } 2 \text { to } \\
\text { search the Internet leisurely, or } \\
\text { for fun }\end{array}$ & 67 & 3.57 & \multirow[t]{2}{*}{0.002} & \multirow[t]{2}{*}{0.953} \\
\hline & & $\begin{array}{l}\text { I prefer to use L2 to search the } \\
\text { Internet leisurely, or for fun }\end{array}$ & 25 & 4.52 & & \\
\hline
\end{tabular}




\begin{tabular}{|c|c|c|c|c|c|c|}
\hline \multicolumn{7}{|c|}{$\begin{array}{c}\text { TABLE } 2 \\
\text { Independent Samples T-Tests }\end{array}$} \\
\hline DV & $\begin{array}{l}\text { Variable } \\
\text { Name }\end{array}$ & IV & $\mathbf{N}$ & Mean & Sig & $\begin{array}{c}\text { Mean } \\
\text { Difference }\end{array}$ \\
\hline \multirow[t]{2}{*}{$\begin{array}{l}\text { Code- } \\
\text { switch }\end{array}$} & \multirow[t]{2}{*}{ Movies } & $\begin{array}{l}\text { I do not prefer to use L2 for } \\
\text { watching movies }\end{array}$ & 58 & 3.19 & \multirow[t]{2}{*}{0.001} & \multirow[t]{2}{*}{1.722} \\
\hline & & $\begin{array}{l}\text { I prefer to use L2 for watching } \\
\text { movies }\end{array}$ & 34 & 4.91 & & \\
\hline \multirow[t]{2}{*}{$\begin{array}{l}\text { Code- } \\
\text { switch }\end{array}$} & \multirow[t]{2}{*}{$\begin{array}{l}\text { Instant } \\
\text { Messaging }\end{array}$} & $\begin{array}{l}\text { I do not prefer to use L2 for } \\
\text { instant messaging }\end{array}$ & 68 & 3.54 & \multirow[t]{2}{*}{0.002} & \multirow[t]{2}{*}{1.081} \\
\hline & & $\begin{array}{l}\text { I prefer to use } \mathrm{L} 2 \text { for instant } \\
\text { messaging }\end{array}$ & 24 & 4.63 & & \\
\hline \multirow{2}{*}{$\begin{array}{l}\text { Code- } \\
\text { switch }\end{array}$} & \multirow{2}{*}{$\begin{array}{l}\text { SMS and } \\
\text { Texting }\end{array}$} & I do not prefer to use L2 for SMS & 69 & 3.45 & \multirow[t]{2}{*}{0.001} & \multirow[t]{2}{*}{1.507} \\
\hline & & I prefer to use L2 for SMS & 23 & 4.96 & & \\
\hline \multirow[t]{2}{*}{$\begin{array}{l}\text { Code- } \\
\text { switch }\end{array}$} & \multirow{2}{*}{$\begin{array}{l}\text { News and } \\
\text { Current } \\
\text { Events }\end{array}$} & $\begin{array}{l}\text { I do not prefer to use L2 for news } \\
\text { and current events }\end{array}$ & 68 & 3.51 & \multirow[t]{2}{*}{0.002} & \multirow[t]{2}{*}{1.194} \\
\hline & & $\begin{array}{l}\text { I prefer to use L2 for news and } \\
\text { current events }\end{array}$ & 24 & 4.71 & & \\
\hline \multirow[t]{2}{*}{$\begin{array}{l}\text { Code- } \\
\text { switch }\end{array}$} & \multirow[t]{2}{*}{ E-mail } & $\begin{array}{l}\text { I do not prefer to use L2 for } \\
\text { communicating on e-mail }\end{array}$ & 73 & 3.63 & \multirow[t]{2}{*}{0.019} & \multirow[t]{2}{*}{0.949} \\
\hline & & $\begin{array}{l}\text { I prefer to use L2 for } \\
\text { communicating on e-mail }\end{array}$ & 19 & 4.58 & & \\
\hline \multirow[t]{2}{*}{$\begin{array}{l}\text { Code- } \\
\text { switch }\end{array}$} & \multirow[t]{2}{*}{$\begin{array}{l}\text { Phone and } \\
\text { Voice Calls }\end{array}$} & $\begin{array}{l}\text { I do not prefer to use L2 on the } \\
\text { telephone or for voice calls }\end{array}$ & 58 & 3.29 & \multirow[t]{2}{*}{0.001} & \multirow[t]{2}{*}{1.442} \\
\hline & & $\begin{array}{l}\text { I prefer to use L } 2 \text { on the } \\
\text { telephone or for voice calls }\end{array}$ & 34 & 4.74 & & \\
\hline \multirow{2}{*}{$\begin{array}{l}\text { Code- } \\
\text { switch }\end{array}$} & \multirow[t]{2}{*}{ L2 at Home } & I do not use L2 at home & 31 & 2.13 & \multirow[t]{2}{*}{0.001} & \multirow[t]{2}{*}{2.559} \\
\hline & & I use L2 at home & 61 & 4.69 & & \\
\hline \multirow{2}{*}{$\begin{array}{l}\text { Code- } \\
\text { switch }\end{array}$} & \multirow[t]{2}{*}{ L2 at School } & I do not use L2 at school & 76 & 3.58 & 0.001 & 1.421 \\
\hline & & I use L2 at school & 16 & 5 & & \\
\hline $\begin{array}{l}\text { Code- } \\
\text { switch }\end{array}$ & $\begin{array}{l}\text { L2 with } \\
\text { Friends }\end{array}$ & $\begin{array}{l}\text { I do not speak L2 with my } \\
\text { friends }\end{array}$ & 51 & 3.02 & 0.001 & -1.81 \\
\hline & & I speak L2 with my friends & 41 & 4.83 & & \\
\hline $\begin{array}{l}\text { Code- } \\
\text { switch }\end{array}$ & $\begin{array}{l}\text { English with } \\
\text { Family }\end{array}$ & $\begin{array}{l}\text { I do not speak English with my } \\
\text { family }\end{array}$ & 41 & 4.07 & 0.002 & 0.446 \\
\hline & & I speak English with my family & 51 & 3.63 & & \\
\hline Code- & L2 with & I do not speak L2 with my family & 29 & 2.14 & 0.001 & 2.465 \\
\hline & & I speak L2 with my family & 63 & 4.6 & & \\
\hline Code- & Comfortable & I am not comfortable with L2 & 50 & 3.14 & 0.001 & -1.503 \\
\hline & & I am very comfortable with L2 & 42 & 4.64 & & \\
\hline Code- & Race and & Not black / African American & 76 & 4.17 & 0.001 & 1.984 \\
\hline & & Black / African American & 16 & 2.19 & & \\
\hline Code- & Race and & Not Asian & 54 & 3.3 & 0.001 & -1.283 \\
\hline & Ethnicity & Asian & 38 & 4.58 & & \\
\hline
\end{tabular}




\begin{tabular}{|l|l|c|c|}
\hline \multicolumn{4}{|c|}{$\begin{array}{c}\text { TABLE 3 } \\
\text { Somers' D Test }\end{array}$} \\
\hline \multicolumn{1}{|c|}{ IV } & \multicolumn{1}{c|}{ DV } & $\boldsymbol{d}$ & $\begin{array}{c}\text { Approximate } \\
\text { Significance }\end{array}$ \\
\hline L2 Speaking & Code-switching & 0.553 & 0.001 \\
\hline L2 Reading & Code-switching & 0.422 & 0.001 \\
\hline English Understanding & Code-switching & -0.305 & 0.003 \\
\hline English Reading & Code-switching & -0.299 & 0.004 \\
\hline English Writing & Code-switching & -0.237 & 0.013 \\
\hline
\end{tabular}

Table 3 shows associations between language ability and CS using Somers' d test. According to Laerd Statistics, "A value of -1 indicates that all pairs of observations are discordant and a value of +1 indicates that all pairs of observations are concordant." 49 Table 3 shows moderate to weak effects.

Reported CS is positively associated with higher L2 speaking and reading ability with a moderate effect strength. Additionally, reported CS has an inverse association with the students' ability to understand, read, and write English. The strength of the inverse association is weak $(-0.305,-0.299,-0.237)$.

\section{Focus Group Data and Analysis}

In the focus groups, all but one of the participants were bilingual (counting English and Jamaican Creole English as separate languages), and the single monolingual speaker of English spoke British English. There were 10 instances of students reporting code-switching in the focus group transcripts. The author also counted instances of switching from American to British English as a CS. Below are select quotes from the transcripts when participants were asked about how they used their languages. The following languages were discussed in the focus groups: English, Vietnamese, Hindi, French, French Creole (Kreyol), Cantonese, Mandarin, Hakka, Armenian, Bengali (Bangla), British English, Patwa (Jamaican Creole), Portuguese, Spanish, Russian, and Ukrainian. The data collected and described in this section illustrate the complexity of code-switching, the use of different languages for different types of information, the importance of community, and the presence of dialects both in English and nonEnglish languages.

A quote that exemplifies the complexity of code-switching is from a Chinese student whose parents do not speak the same variety of Chinese. The student referred to the Hakka language as a "dialect," describing her upbringing in a multi-Chinese dialect household, where neither of her parents spoke English very well. She explained that if she doesn't want her parents to understand what she is saying she switches to English as her secret language. This quote from her is also illustrative of the linguistic diversity of Chinese languages:

"Yeah, when I am in school. Of course, most of the time I speak English in school. When I go home, I speak to my dad, my mom. I talk with my mom in dialect. Because she doesn't know how to speak Mandarin. My dad speak to me in dialect. I respond back in Mandarin because my dad is not much good. Not much fluent in the dialect. But my dad I can hear and listen. You know, for my sisters, my brothers, I speak in like half English, half dialect, and maybe some has just like all everything mixed one or I don't want to know what my parents to know what I am talking about, I speak English." 
A female Colombian undergraduate student described which languages she uses for different types of information:

"I do like Spanish literature. When it comes to reading for pleasure, 50/50 for Spanish and English. I read a lot of religion in Spanish. Research, I don't. And it's a little limited in Spanish, because my entire college career has been in English. So even when I've tried, it's difficult. I've done it, like when I travel back home. Or if I'm trying to read a text that's in Spanish, and it's academic, it takes a little bit of work. Because I have the information in my head in English."

The same student also said:

"I pretty much read what I come across. As long as it's interested, is interesting, and I'm interested in it. I don't really have a preference with the news per se. I have always read the Bible in Spanish. Family and friends, and music. It's like $80 \%$ in Spanish, 20\% in English. Television is mostly English, just because lack of good stuff (laughter). Seriously. All those telenovelas, get out! So that's out."

Academic vocabulary in English and Spanish is learned. This student is obviously a fluent Spanish speaker and reader, but she knows her academic discipline in English only so she cannot readily code-switch to Spanish for academic tasks.

Community plays an important role in CS and, because this male Indian graduate student does not have a community of Bengali speakers, he has limited ability in Bengali. But his comprehension is maintained through preference for Bengali music:

"For research, basically I do everything in English because I have little family and friends here and back home so I can barely speak in Bengali. Other than that, I use English everywhere. For research, I follow the Wall Street Journal and the Economist. I don't follow Bengali newspapers. Per se about music, I prefer Bengali, and Hindi, and English as well."

This quote illustrates how a language may not manifest in one ability (like speaking) but can still be used and enjoyed for other kinds of information (music, movies, oral poetry, etc.). And when probed about mixing Hindi and English, the male Bengali student said, "Yeah. It's Hinglish. Hindi and English. Yeah."

English, like any language, has dialects. An undergraduate student from Grenada described how British English influences the kinds of information sources she seeks: "Yeah, in Grenada we're more influenced by the British, so the spelling of our words are along the British standard." And when probed about her preferences for British English sources, she said:

"Yes, maybe because I'm familiar with it. If I go on the Internet, I would look up bbc. uk. I'm only here three years, so I'll go back and forth. So it's not like I'm going to assimilate into the culture. I'm just like an outsider looking in. I feel most comfortable with the British way of news, expressing, so their writing. I don't know how to explain. It's so different here. When I did A levels, years ago. It's just a whole different experience. I started at a community college, BMCC [Borough of Manhattan Community College]. It was like A level all over again, although it was an associate degree. I had to focus on the spelling of the words, how we spell color and you spell color. C-o-l-o-u-r, we spell it different. It was just, no other difficulty really." 
This is an example of how culture influences information seeking. This preference for British sources was verified by the two other Jamaican students who also spent some of their formative education in Jamaica.

This female Bengali undergraduate student uses Bengali exclusively with her family:

"So in school I speak in English. And I live with my aunt. And she works 14 hours a day, so I hardly see her. Whenever I see her for half an hour or an hour, we're going to talk in Bangla [Bengali], but we don't like mix stuff. Some of the words are in English. Like we don't have a word for chair that's in Bangla. So some of the words has to be in English. But um, most of the cases we don't mix two languages. And even when I'm talking to my parents I'll be talking Bangla."

In response to a probe about making friends in school, this student noticed that the variety of Bengali spoken by the students she meets in Brooklyn contain an unusual accent. This is an example of the linguistic diversity that can exist in the same language between diaspora speakers and recently arrived speakers. Her CS shows that she enjoys and uses her languages for a variety of information consumption:

"I have met like a couple of Bangladeshi people in the school. But as she was saying, they don't speak Bangla. What I feel they have really weird accent when they speak in Bangla. I feel weird when they speak in Bangla. So they like speak okay, if you speak comfortable speaking in English, I don't have a problem. And in case of music, I feel like I'm more into Bangla and Hindi music. More than English music. English music is okay,.... If I listen to a song I'll only listen to like, once or twice. But if I'm gonna listen to music, like the whole day, it has to be Bangla and Hindi. And even in the case of movies or soaps. I watch a lot of English soaps. Like I watched How I Met Your Mother, the whole 9th season. And I watch like Scrubs, and Big Bang Theory. And what's the other one? I like watching CSI and Breaking Bad. ... Yeah sorry, Breaking Bad."

The following quote from a male Vietnamese undergraduate student shows his sophistication when looking for news about his home country: "I do read Vietnamese news and writings that's about Vietnamese because I want to know what's going on at the university. We still have government controlled media. So sometimes the news has bias. I like Vietnamese pop, for my personal life." This male Chinese undergraduate student, after multiple probes, simply stated that both English and Chinese are important in his life: "I think the language is important, because I prefer the both language in my life for my enjoyment."

The focus group data clearly show that multilinguals are using languages in different ways to consume and communicate information; they are switching readily in their daily lives before going to school, at school, and after school. These data highlight the complex and fluid ways language and culture influence how multilingual foreignborn students consume information. It's important to note that within large language categories exist smaller subgroupings or varieties, whether they are varieties of English or Chinese dialects. These language groupings are not homogeneous populations, and care should be taken by academic librarians to acknowledge these differences in both accent and grammaticality. Interactions with foreign-born students should focus on communicating and not correcting.

\section{Discussion}

The survey and data provide evidence of CS in foreign-born students in academic 
environments like the library at Brooklyn College ("I use L2 at school," $P<.001, M D=$ 5 ) and most likely with co-ethnic friends ("I speak L2 with my friends," $P<.001, M D$ $=1.81$ ). The data show that students who report a second language are more likely to use it for a variety of information tasks like searching the Internet, consuming media, and communicating through social media or similar texting mediums, as shown in table 1 . These data show that home is the place that L2 speakers will most likely codeswitch $(P<.001, M D=2.559)$. They also show that L2 is used for academic purpose like reading $(P<.05, M D=.644)$, especially for news and current events $(P<.001, M D$ $=1.194$ ). The moderate association in table 2 between code-switching, L2 speaking, and L2 reading needs to be further investigated. Does it suggest that people who speak and read a language are more engaged in that language? It's difficult to tell and is further complicated for languages that don't have a strong print culture (Creoles, for example). The inverse association between English ability and CS is also interesting in that the higher the ability reported in English comprehension, reading, and writing, the lower the likelihood for CS. Brooklyn College library is a multilingual space, as the survey data show, and the language environment of foreign-born students is complex and fluid.

An important detail about the data collected in the survey is that 38 of the 92 respondents self-identified as Asian, and they are more likely than any of the other demographic category surveyed to code-switch $(P<.001, M D=1.283)$. Additionally, there were respondents from the Caribbean who did not self-identify with the category of black/African American; they chose the "other" response to write in Caribbean. Similarly, there were Bengali students who did not choose to self-identify with Asian (the author considered, but did not include, a category for South Asian), and several of the respondents wrote in Bengali by selecting the "other" category. It was unfortunate that there were very few Hispanic foreign-born students, since Spanish is widely spoken in New York City.

Furthermore, it's important to think about how Creole languages do not really appear in more formal academic language domains. For example, there are no calculus books written in Haitian Kreyol as there would be calculus books written in Vietnamese, Mandarin, or Spanish. Another question that these survey data cannot effectively comment on is CS for speakers of other varieties of English, like British English: do those speakers code-switch across varieties of English? For example, would the Trinidadian student from the focus group have reported in the survey or even be conscious of Americanizing her spelling and accent to function in an American English academic environments; is that a form of code-switching? These finite, qualitative distinctions are difficult to tease out in a survey. Fortunately, the focus group data show and identify some of these experiences and processes.

\section{Synthesis of the Survey and Focus Group Data}

This section discusses two instances when the quantitative findings are complemented by the qualitative findings. There is one instance when the quantitative findings are contradicted by the qualitative data.

Both data sets in this study capture the importance of CS at home. The survey data correlate that home is an important place for language use, and the narrative from the Chinese student who speaks various dialects of Chinese and English with her parents, brothers, and sisters reveals the complexity of her language use. Both data sets show that there is diversity within Chinese and that, as librarians who value linguistic diversity, it is important to be aware that Chinese is not a monolithic language or cultural category. The application to practice is clear: if a library has large groups of Chinese speakers, it will be important to know and identify which cultural and linguistic groups use the academic library. 
The second pattern found in both data sets includes the influence of language over the preference for consuming information like academic reading and news. The findings suggest that it is likely that students will code-switch in academic reading contexts and when reading news. The focus group data give us more insight into this information behavior. For example, the data from the Colombian undergraduate student tell us that her code-switching is in very specific domains, like leisurely reading and religious reading, and that she has difficulty reading academic Spanish. This information is important to know for building collections and for supporting students who may want to take their academic experiences to their home country for an internship, for a job, or for pursuing graduate work. In this study we also see how dialect preferences in English influence how Caribbean speakers gravitate toward the British Standard English with consuming news and current events, which is also an example of dialect-switching. These data showing how English dialects can affect information behavior is important for helping librarians understand that, not only is there diversity across languages, there are dialectal differences within major language groups like English, Chinese, Spanish, and others.

The third pattern found in the survey, that students are more likely to use L2 with friends, is contradicted by the example of the female Bengali student who finds that Bengali accents spoken by Brooklyn students are unusual. Again, while students are likely to switch with friends, students who have just arrived may not have friends who speak the same dialect. This is important when distinguishing between immigrant students and international students when it comes to conducting further studies of co-ethnic language use in academic libraries.

Future studies involving code-switching should focus on capturing both quantitative and qualitative data. It's just as important to understand individual experiences and processes around code-switching, because this helps in interpreting the statistical data. Qualitative data can also reveal missed or new variables that will give the researcher better insight into the relationships between language and information.

\section{Limitations}

This survey and analysis contain some limitations that should be kept in mind when considering the findings. The first limitation is the nature of self-reported usage data, though the author attempted to increase the internal reliability of the data by using focus groups to triangulate the results. The second limitation is related to sampling: the focus groups were very small, and the survey was a convenience sample. Third, income as a variable was collected as a rough estimate using ACS 2014 data by zip code. This is not the best way to capture income data, but it does provide some information. Finally, it should be noted that many of the terms used throughout this article, including race, gender, ethnicity, and immigration status, are social science terms often used in survey research; their use is not meant to give offense or intentionally exclude any groups. There is always some aspect of reductionism that occurs in survey-based research, and the author welcomes feedback on how to make the survey categories more inclusive.

\section{Implications for Academic Library Services}

CS is a well-established phenomenon outside of library and information science, and this paper aimed to introduce librarians to this concept and document this behavior in an academic library setting. There are many implications of CS for academic library services, especially in the area of linguistic diversity, standard 6 of ACRL's Diversity Standards: Cultural Competency for Academic Libraries, which reads: "Librarians and library staff shall support the preservation and promotion of linguistic diversity, and work to foster a climate of inclusion aimed at eliminating discrimination and oppression based on linguistic or other diversities." 50 
The data from this study provide evidence that language influences the information behavior of students in the form of code-switching and dialect switching. More research could be done to investigate information code-switching, which the author has broadly defined as changing languages or dialects for particular information tasks. This kind of research would allow librarians to map language use, language choice, and language preferences of students to actual library collections, services, and resources. Furthermore, this research would be valuable for serving first-generation college students, generation 1.5 students, international students, and immigrant students.

Another area of critical importance is being inclusive of non-English languages in collection development: "collection managers should be attentive to represent the linguistic needs of library constituents, and assure that library resources in print or electronic formats are available, especially to support the academic curricula reflecting all diversity issues, including those of visually disabled constituents." ${ }^{51}$ Increasing the visibility of non-English scholarly sources can be as simple as creating library guides that show students how to access peer-reviewed journals and open access indexes in non-English languages. Engaging with the scholarly literature in non-English languages is particularly important in the social sciences. For example, librarians could create a guide that would allow Spanish-speaking students of urban sociology to engage with and synthesize sociological ideas in Spanish language journals with concepts from English language journals. The practice of incorporating non-English sources into English-language papers is a long scholarly tradition in the humanities. Language access is also an important concept in the diversity standards: "Provide and advocate for the provision of information, reference, referrals, instruction, collection management, and other services in the language appropriate to their constituencies, including the use of interpreters." As the CS data suggest, our libraries are not monolingual spaces, so making sure that printers can print in different scripts (and in general having technology capable of supporting users' linguistic preferences), as well as having welcome signage in other languages are steps that libraries can take to make non-English speakers feel more included when using the library as a space for studying or meeting with classmates. Ideally, supporting linguistic diversity in academic libraries would include multilingual staff who could create library instruction and other academic library services that cater to large linguistic populations served by the academic library.

\section{Conclusion}

The purpose of this study was to explore language use, language choice, and language preferences in academic libraries, and the author found evidence for code-switching patterns in both qualitative and quantitative data. In the analysis, the author maintains that code-switching patterns are correlated with information tasks and argues that more research could be done on information code-switching to give librarians data on language use and apply those data to library services. For the foreign-born students analyzed in this study, it is clear that their culture and their non-English language represent an active and important part of their identity, information consumption, and academic socialization. In their language choice for information, there is enough statistically significant evidence for information code-switching, when students switch languages for a particular information task. Yet, in most of the academic library literature, these active language communities, their patterns of use, and their preferences have not been the subject of research. These data show that Brooklyn College Library is a rich multilingual space, yet there are only a few studies that discuss multilingualism in academic libraries. What can academic librarians do with these kinds of data? 
There are many practical recommendations relating to linguistic diversity, including creating a multilingual-friendly environment. Reference assistance could include offering specialized library instruction or orientations for immigrant students, firstgeneration college students, and international students. Public services staff could also receive linguistic diversity training that includes information on ESL and EFL populations. Linguistic diversity training might also focus content on creating sensitivity and awareness of patrons who are linguistic minorities (for example, Spanish speakers who speak other Central American languages such as Mayan languages), as well as information about Creoles and pidgins, how accents work, nonwritten languages, and varieties of spoken English that may be relevant to the patron population. Computer labs can be language-friendly, with a variety of keyboard formats and printers available for people who need to print e-mails, share notes, and look up concepts in languages other than English. In the focus group interview with the Colombian undergraduate student, she spoke about wanting to gain some experience working in Colombia; however, she lacked the Spanish academic vocabulary to be competitive. To help students like her, academic librarians could create LibGuides for non-English scholarly sources that include Latindex, for example (www.latindex.unam.mx/latindex/ inicio). Libraries could focus on hiring multilingual librarians. There is clearly a need for more research in transnationalism, especially in academic libraries that have a high number of foreign-born students. Are these students trying to use their American college degrees and create transnational careers that take advantage of their cultural capital? Are academic libraries spaces currently treated as monolingual rather than multilingual spaces? How does this affect our practice, and how can libraries change to support these students in their information needs? Monica Jacobe, director of the Center for American Language \& Culture at The College of New Jersey, speaks about immigration trends in student success:

First-generation college students will no longer be primarily American-born students from working class families. Instead, many more students in that category will be recent immigrants, born all over the world, who completed high school in the U.S. For many schools, they will "look" on paper like domestic applicants, but the support they need will be very different.

How can academic librarians imagine a shift from monocultural and monolingual approaches to multilingual approaches? And what services will need to be rethought? These are the kinds of questions additional studies on language use and libraries can answer. CS is just one conceptual tool from sociolinguistics that has very practical applications in our work with international and immigrant students.

\section{Notes}

1. Barbara E. Bullock and Almeida Jacqueline Toribio, "Themes in the Study of Code-Switching," in The Cambridge Handbook of Linguistic Code-Switching, eds. Barbara E. Bullock and Almeida Jacqueline Toribio, Cambridge Handbooks in Linguistics (Cambridge; New York: Cambridge University Press, 2009), 1-19.

2. Jan-Peter Blom and John J. Gumperz, "Social Meaning in Linguistic Structure: CodeSwitching in Norway," in Directions in Sociolinguistics: The Ethnography of Communication, eds. John J. Gumperz and Dell Hymes (New York: Blackwell, 1986), 409.

3. Ibid., 411.

4. Ibid.

5. Carol Myers-Scotton, "The Rise of Codeswitching as a Research Topic," in Social Motivations for Codeswitching: Evidence from Africa (Oxford: Clarendon Press, 1995), 57.

6. Joshua Fishman, "Domains and the Relationship between Micro- and Macro-Sociolinguis- 
tics," in Directions in Sociolinguistics: The Ethnography of Communication, eds. John J. Gumperz and Dell Hymes (New York: Blackwell, 1986), 441.

7. Ibid., 442-43.

8. L.B. Breitborde, "Levels of Analysis in Sociolinguistic Explanation: Bilingual Code Switching, Social Relations, and Domain Theory," International Journal of the Sociology of Language 1983, no. 39 (Jan. 1983): 19. 447.

9. Fishman, "Domains and the Relationship between Micro- and Macro-Sociolinguistics,"

10. Ibid., 448.

11. Alejandro Portes and Rubén Rumbaut, "Children of Immigrants Longitudinal Study (CILS), 1991-2006," Children of Immigrants Longitudinal Study (CILS), 1991-2006 (ICPSR 20520), 2009, available online at www.icpsr.umich.edu/icpsrweb/RCMD/studies/20520 [accessed 24 March 2015].

12. Breitborde, "Levels of Analysis in Sociolinguistic Explanation," 5.

13. Shana Poplack, "Sometimes I'll Start a Sentence in Spanish Y Termino En Español: Toward a Typology of Codeswitching," Linguistics 18, no. 7/8 (1980): 581-618, doi:10.1515/ling.1980.18.7-8.581.

14. Ibid., 583.

15. Ibid., 584.

16. Ibid., 600.

17. Ibid., 610.

18. Jannis Androutsopoulos, "Language and the Three Spheres of Hip Hop," in Global Linguistic Flows: Hip Hop Cultures, Youth Identities, and the Politics of Language, eds. H. Sammy Alim, Awad Ibrahim, and Alastair Pennycook (New York: Routledge, 2009), 54-58.

19. Elena Seoane, "World Englishes Today," in World Englishes: New Theoretical and Methodological Considerations, eds. Elena Seoane and Cristina Suárez Gómez, Varieties of English around the World G57 (Amsterdam; Philadelphia: John Benjamins Publishing Company, 2016$), 1$.

20. Marta Fairclough and Flavia Belpoliti, "Emerging Literacy in Spanish among Hispanic Heritage Language University Students in the USA: A Pilot Study," International Journal of Bilingual Education and Bilingualism 19, no. 2 (Mar. 3, 2016): 185-201, doi:10.1080/13670050.2015.1037718.

21. Ibid., 186.

22. Ibid., 189.

23. Magdalena Malechová, "Multilingualism as a Sociolinguistic Contact Phenomenon with Regard to Current Forms of Multilingual Communication Code-Switching as One of the Contemporary Communication Trends," Višejezičnost Kao Sociolingvistički Fenomen Kontakta Imajući U Vidu Suvremene Oblike Višejezične Komunikacije Mijenjanje Kodova Kao Suvremeni Komunikacijski Trend 49, no. 1/2 (July 2016): 86-93.

24. Ibid., 91.

25. Bettina Kümmerling-Meibauer, "Code-Switching in Multilingual Picturebooks," Bookbird: A Journal of International Children's Literature (Johns Hopkins University Press) 51, no. 3 (July 2013): $12-21$.

26. Ibid., 19.

27. Amanda B. Click, Claire Walker Wiley, and Meggan Houlihan, "The Internationalization of the Academic Library: A Systematic Review of 25 Years of Literature on International Students," doi:10.5860/crl.v78i3.16591.

28. Nadia Caidi, Danielle Allard, and Lisa Quirke, "Information Practices of Immigrants," Annual Review of Information Science and Technology 44, no. 1 (Jan. 1, 2010): 515, doi:10.1002/ aris.2010.1440440118.

29. Ignacio J. Ferrer-Vinent, “For English, Press 1: International Students' Language Preference at the Reference Desk," Reference Librarian 51, no. 3 (Sept. 2010): 189-201, doi:10.1080/02763871003800429.

30. Karen Bordonaro, "Is Library Database Searching a Language Learning Activity?" College $\mathcal{E}$ Research Libraries 71, no. 3 (May 2010): 273-84.

31. Sara Luly and Holger Lenz, "Language in Context: A Model of Language Oriented Library Instruction," Journal of Academic Librarianship 41, no. 2 (Mar. 2015): 140-48, doi:10.1016/j. acalib.2015.01.001.

32. Frans Albarillo, "Is the Library's Online Orientation Program Effective with English Language Learners?" College \& Research Libraries, 78, no. 5 (July 2017): 656-59, doi:10.5860/crl.78.5.652.

33. Sonia Smith, "Library Instruction for Romanized Hebrew," Journal of Academic Librarianship 41, no. 2 (Mar. 2015): 197-200, doi:10.1016/j.acalib.2014.08.003.

34. Ibid., 199.

35. Molavi Fereshteh, "Main Issues in Cataloging Persian Language Materials in North America," Cataloging \& Classification Quarterly 43, no. 2 (Dec. 8, 2006): 77-82, doi:10.1300/J104v43n02_06.

36. Kim SungKyung, "Romanization in Cataloging of Korean Materials," Cataloging \& Clas- 
sification Quarterly 43, no. 2 (Dec. 8, 2006): 53-76, doi:10.1300/J104v43n02_05.

37. Hikaru Nakano, "Non-Roman Language Cataloging in Bulk: A Case Study of Japanese Language Materials," Cataloging \& Classification Quarterly 55, no. 2 (Feb. 2017): 75-88, doi:10.108 0/01639374.2016.1250853.

38. Albarillo, "Is the Library's Online Orientation Program Effective with English Language Learners?" 3.

39. Xiang Li, Kevin McDowell, and Xiaotong Wang, "Building Bridges: Outreach to International Students via Vernacular Language Videos," Reference Services Review 44, no. 3 (July 2016): 325, doi:10.1108/RSR-10-2015-0044.

40. Misa Mi and Yingting Zhang, "Culturally Competent Library Services and Related Factors among Health Sciences Librarians: An Exploratory Study," Journal of the Medical Library Association 105, no. 2 (Apr. 2017): 135, doi:10.5195/jmla.2017.203.

41. Ibid., 136.

42. Ibid., 133.

43. Institutional Research and Data Analysis at Brooklyn College, City University of New York, "Fall 2014 Final Enrollment Reports, Enrollment Table 21 Country of Birth," available online at www.brooklyn.cuny.edu/bc/offices/avpbandp/ipra/enrollment/F14/Enrollment-Table21.pdf [accessed 20 November 2016].

44. United States Census Bureau, "American FactFinder," available online at http://factfinder. census.gov/faces/nav/jsf/pages/index.xhtml [accessed 20 November 2016].

45. Laerd Statistics, "Independent-Samples T-Test Using SPSS Statistics," Statistical Tutorials and Software Guides (2015), available online at https://statistics.laerd.com [accessed 21 November 2016].

46. Laerd Statistics, "Somers' D Using SPSS Statistics," Statistical Tutorials and Software Guides (2016), available online at https://statistics.laerd.com [accessed 21 November 2016].

47. Arlene Fink, How to Conduct Surveys: A Step-by-Step Guide (Los Angeles: SAGE, 2013), 45.

48. Executive Office of the President, Office of Management and Budget, "Revisions to the Standards for the Classification of Federal Data on Race and Ethnicity," The White House, available online at https://www.whitehouse.gov/node/15626 [accessed 21 November 2016].

49. Laerd Statistics, "Somers' D Using SPSS Statistics."

50. Association of College and Research Libraries, "Diversity Standards: Cultural Competency for Academic Libraries" (2012), available online at www.ala.org/acrl/standards/diversity [accessed 30 August 2016].

51. Racial and Ethnic Diversity Committee Members, "Diversity Standards: Cultural Competency for Academic Libraries (2012)," Association of College and Research Libraries, available online at www.ala.org/acrl/standards/diversity [accessed 21 November 2016]. 